\title{
LATIFÚNDIO, CONFLITO E DESENVOLVIMENTO NO VALE DO JARI: DO AVIAMENTO AO CAPITALISMO VERDE
}

\section{LATIFUNDIO, CONFLICTO Y DESARROLLO EN EL VALLE DEL JARI: DEL SISTEMA DE HABILITACIÓN AL CAPITALISMO VERDE \\ LARGE ESTATE, CONFLICT AND DEVELOPMENT IN THE VALLEY OF JARI: FROM THE AVIAMENTO TO GREEN CAPITALISM}

\author{
Ricardo Folhes ${ }^{1}$ \\ Maria Luíza Camargo ${ }^{2}$
}

\begin{abstract}
RESUMO: Este artigo pretende reconstituir traços da história de exploração de um imenso latifúndio existente no vale do rio Jari, nos estados do Pará e Amapá. Formado numa época em que o sistema de aviamento constituía o poder político e econômico de coronéis da borracha e, em decorrência, a sujeição de extrativistas, o latifúndio, depois de quase um século, torna-se exemplo mundial de boas práticas socioambientais, sendo reconhecido como exemplo pioneiro de "empresa verde". Porém, atualmente, a empresa controladora do latifúndio encontra-se envolvida em sérios conflitos com posseiros e envolta em processos judiciais que apuram a grilagem das áreas que ocupa e as irregularidades do plano de manejo florestal em atividade. Pretende-se, aqui, discutir as trajetórias das populações rurais que ali existiam ou para lá foram ao longo do processo de ocupação do vale do Jari e do latifúndio, à luz das diferentes estratégias econômicas adotadas e, junto a dados de campo coletados entre novembro de 2010 e novembro de 2011, descrever parte dos conflitos territoriais existentes.
\end{abstract}

Palavras-chave: Projeto Jari; Amazônia brasileira; conflito territorial, Grupo Orsa, grilagem.

RESUMEN: Este artículo se propone reconstruir segmentos de la historia de explotación de un inmenso latifundio localizado en el valle del río Jari, en los estados de Pará y Amapá. Formado en una época en la que el sistema de habilitación constituía el poder político y económico de los barones del caucho y por consiguiente, la sujeción de los extractores, el latifundio se convierte, después de casi un siglo, en un ejemplo mundial de buenas prácticas socioambientales, considerándose un ejemplo pionero de "empresa verde". No obstante, la empresa que controla el latifundio se encuentra actualmente inmersa en graves conflictos con los habitantes y también está involucrada en procesos judiciales que investigan la apropiación de las áreas que ocupa (land grabbing) y las irregularidades del plan de manejo forestal en activo. El objetivo

\footnotetext{
${ }^{1}$ Bolsista CAPES. Doutorando em regime de cotutela no Programa de Pós-Graduação em Ciências Ambientais (PPGCA) da Universidade Federal do Pará e no Instituto de Altos Estudos da América Latina (IHEAL / CREDA) da Université Sorbonne Nouvelle - Paris 3: rfolhes@gmail.com

2 Bolsista CAPES. Mestranda do Programa de Pós-Graduação em Geografia Humana-USP. E-mail: malucamargo80@gmail.com
} 
115 AGRÁRIA, São Paulo, No. 18, 2013 FOLHES, R. e CAMARGO, M. L.

que se persigue es debatir las trayectorias de las poblaciones rurales que habitaban en este lugar o que se habían desplazado hasta él durante el proceso de ocupación del valle del Jari y del latifundio, así como describir parte de los conflictos territoriales existentes a la luz de las diversas estrategias económicas adoptadas y empleando datos de campo recogidos entre 2010 y 2011.

Palabras clave: Proyecto Jari; Amazonas brasileña, conflicto territorial, Grupo Orsa, land grabbing.

ABSTRACT: This article discusses the history of the exploitation of one of the largest land estates of the world, based in the Jari River valley, in the states of Pará and Amapá, Brazil. Several million hectares of virgin forest were gathered in the $19^{\text {th }}$ century, at a time when the aviamento system would empower the "rubber' barons", at the expense of local extractivist peasants. Though it was initially constituted by the social subjugation of local populations, a century later, the Jari Project has become a pioneering example of "green capitalism"; the company is world-renowned and rewarded for its social and environmental practices. Meanwhile, the head company is today involved in serious social conflicts with local peasants, and is being investigated for land grabbing and irregularities in the forest management. In this paper, we intend to recount the history and economic strategies of the populations that lived in the Jari Valley throughout its process of occupation and exploitation by private companies. We will describe as well some of the issues raised by actual territorial conflicts.

Key words: Jari Project; Brazilian Amazon; territorial conflict, Orsa Group, land grabbing.

\section{INTRODUÇÃO}

No final dos anos 1960, um grande projeto econômico foi implantado no vale do Rio Jari, um afluente da margem esquerda do Baixo Amazonas, marco natural da divisa dos Estados do Pará e Amapá. Trata-se do empreendimento que ficou conhecido como Projeto Jari, idealizado pelo bilionário norte-americano Daniel K. Ludwig, que, com forte apoio do governo militar, operou por quase duas décadas um dos maiores latifúndios do mundo. Após receber centenas de milhões em incentivos na onda dos grandes projetos para a Amazônia das décadas de 1960 e 1970, e acumular escândalos e prejuízos, em 1982 o Projeto foi assumido por um grupo de empresas nacionais e, em 1999 passou para o 
comando do Grupo Orsa, um conglomerado paulista do setor de papel e celulose. A estratégia de exploração econômica do latifúndio passou por várias fases. Do sistema de aviamento, em seu início, passando pela modernização das relações trabalhistas na época de Ludwig, a exploração econômica do latifúndio é atualmente reconhecida como exemplo pioneiro de "empresa verde" e são muitos os prêmios recebidos como reconhecimento de sua responsabilidade social e ambiental, embora, haja sérios conflitos com posseiros e processos

judiciais que apuram a grilagem de terras e as irregularidades do plano de manejo florestal em atividade.

Este trabalho se propõe a retratar a história de exploração econômica do latifúndio, analisando as diferentes estratégias utilizadas e sua relação com as trajetórias de pessoas que ali nasceram ou para lá foram em diferentes épocas e situações com o objetivo de se aproximar os conflitos fundiários atualmente existentes.

\section{A FORMAÇÃO INICIAL DO LATIFÚNDIO}

Os registros mais antigos da região do rio Jari datam de meados do século 18 e tratam da formação da cidade de Almeirim, que fica às margens do Amazonas e tem sua origem na Aldeia Paru fundada por frades capuchinhos de Santo Antonio e indígenas descidos do "centro", de igarapés distantes do leito dos grandes rios.

Apenas em 1890, após a Proclamação da República e já no auge da exploração gomífera na Amazônia, Almeirim se tornou município. No primeiro Conselho Municipal, eleito em 1891, tomou posse como vogal José Julio de Andrade, figura emblemática da região e responsável pela formação, ainda no século 19, do latifúndio onde, dezenas de anos mais tarde, teria lugar o Projeto Jari. 
José Julio de Andrade, cearense de Sobral, chegou à região do rio Jari por volta de 1882 , período em que se intensificou a migração de nordestinos para a região Amazônica, devido à grande seca ocorrida nesta região no final da década de $1870^{3}$. Em pouco mais de uma década, se tornou um dos homens mais influentes do vale do Jari graças ao poder obtido com a exploração de castanha, seringa e balata, chegando, inclusive, a senador do estado Pará. Acumulou uma enorme extensão de terras que, se tomada como referência a divisão política atual, se estenderia pelos estados do Amapá e Pará, nas duas margens do rio Jari. As circunstâncias nas quais obteve essas áreas são rodeadas de relatos de fraudes eleitorais e nos cartórios da região ${ }^{4}$, dando início a uma complicada situação fundiária até hoje sem solução. O título de posse de apenas uma de suas glebas, a Fazenda Saracura, por exemplo, remetia a uma área de 2,6 milhões de hectares: se cartografada conforme a descrição contida na escritura iria até o mar do Caribe.

$\mathrm{Na}$ época de José Julio, castanhais e seringais eram explorados pelo sistema de aviamento, garantindo o poder econômico e político dos donos de "barracão" e de controladores de empresas exportadoras.

"Aviar", na Amazônia, significa "fornecer mercadorias a crédito" (SANTOS, 1980, p. 159). Crédito, porém, praticamente sem dinheiro, baseado no escambo, "a melhor modalidade de disfarçar a usura e outros meios de exploração" (SANTOS, 1980, p. 156). O aviamento era um sistema organizado em cadeia bastante concentrador de renda: na base, o coletor, extorquido "até o ponto da intolerância fisiológica" (SANTOS, 1980, p. 162), e, no cume, as empresas exportadoras sediadas em Belém e Manaus, as principais beneficiárias do sistema, relacionando-se diretamente com o mercado internacional. Entre esses dois extremos, um ou mais "aviadores" eram responsáveis pelo fluxo de mercadorias até os extratores e da borracha até as "casas aviadoras", de onde era exportada. Como salienta SANTOS (1980, p. 163), a menor parcela de

\footnotetext{
${ }^{3}$ Sobre a relação entre as secas no Nordeste e as migrações para a região Norte ver SANTOS, 1980.

4 "Levava de Belém atas de eleições e as preenchia em Aramanduba [localidade que abrigava um dos maiores barracões de aviamento controlado por Zé Júlio], em nome de todos os eleitores, em favor do candidato político que apoiava. Em troca, os políticos lhe concediam títulos de posse e protegiam manobras de cartório para a incorporação de terras alheias" (PINTO, 1986, p.16.).
} 
excedente vinha da diferença entre os preços pelos quais o aviador comprava e vendia a borracha, sua principal fonte eram os lucros e juros gerados pela venda de bens de consumo ao extrator. Os preços extorsivos cobrados pelo aviador pretendiam, muito mais do que a aferição de lucro, um controle da mão de obra por meio do endividamento (WEINSTEIN, 1993).

Eram muitos os mecanismos mobilizados para se obter esse excedente. Na maioria das vezes, o coletor chegava ao seringal endividado: eram-lhe cobrados os custos da viagem e as ferramentas necessárias para o trabalho. Além disso, devido ao isolamento ou coerção, os vínculos eram exclusivos com um aviador, que estabelecia tanto o preço pago pela produção, como o das mercadorias vendidas, restando ao seringueiro e ao castanheiro sujeitar-se. Havia ainda um sistema de punição e condenação, amparado pela polícia, para se evitar desvios e fuga dos envidados.

Diante desse quadro, não é difícil imaginar a insatisfação dos extrativistas com as condições de vida e de trabalho. Um exemplo da insatisfação dos extrativistas com as condições de trabalho impostas por Zé Júlio de Andrade foi o episódio ocorrido em 1928, conhecido como Revolta do Cezário. Durante a revolta, um grupo de trabalhadores liderados pelo migrante riograndense do norte José Cezário de Medeiros, tomou um barco obrigando um capataz do latifúndio a aceitar a fuga de centenas de extrativistas para Belém, onde denunciaram para as autoridades da capital a exploração do trabalho em curso no Jari ${ }^{5}$. A visibilidade dada ao conflito, talvez tenha contribuído com os opositores políticos do Coronel José Júlio de Andrade. Alguns anos depois, uma série de acontecimentos foi enfraquecendo politicamente o Coronel. 0 movimento tenentista estabeleceu-se em Belém, abalando o poder dos velhos políticos. Magalhães Barata, governador do Pará nos períodos de 1930-35 e

\footnotetext{
${ }^{5}$ A Revolta de Cezário foi romantizada no livro "Jari - 70 anos de história", escrito por Cristovão Lins, ex-diretor da Jari Celulose, que nas 235 páginas de sua obra procura mostrar a importância histórica da existência do latifúndio para o desenvolvimento regional do Pará. Em seu livro, a Revolta de Cezário é narrada como uma revolta passional motivada por um adultério. No entanto, os mais importantes registros desse levante popular estão presentes numa literatura de cordel produzida por um poeta de Almeirim.
} 
119 AGRÁRIA, São Paulo, No. 18, 2013 FOLHES, R. e CAMARGO, M. L.

1943-45, opôs-se a José Julio, ameaçando prendê-lo. O coronel, então, refugiouse no Rio de Janeiro e, em 1948, vendeu suas terras no Jari para um grupo de empresários, a maioria portugueses.

No "tempo dos portugueses" - como o período ficou conhecido - cresceu a criação de gado, porém o extrativismo continuou como a atividade mais importante da região, ganhando destaque a exploração madeireira nas várzeas ${ }^{6}$, juntamente com o lucro advindo do transporte da produção extrativista regional.

$\mathrm{Na}$ época dos portugueses perdura o sistema de aviamento, as condições de trabalho e as comunidades formadas por agroextrativistas, pescadores e pequenos criadores que, por meio do aviamento, participavam da estratégia econômica do latifúndio.

\section{O VALE DO JARI E A ERA DOS GRANDES PROJETOS}

Em 1967, Daniel Keith Ludwig, um bilionário norte-americano, compra a área e as três empresas pelas quais os portugueses atuavam na região. 0 projeto de Ludwig, logo conhecido como "Projeto Jari", visava à implantação de um complexo agroindustrial, que tinha como carro chefe a produção de celulose em larga escala. Para tanto, Ludwig mandou construir no Japão uma indústria com capacidade para produção de 750.000 toneladas, e uma usina termoelétrica para produção de energia que, depois de construídas, vieram rebocadas para o Jari. Também faziam parte das estratégias econômicas um projeto agropecuário para a produção de arroz e criação de gado, e outro de exploração mineral, para a extração de caulim e de bauxita.

Com Ludwig ocorreu uma substancial transformação no Vale: introduziuse ali um novo modo de exploração dos recursos que não mais dependia do sistema de aviamento, estabeleceu-se outro tipo de relação com a mão-de-obra

\footnotetext{
${ }^{6}$ A atividade madeireira ganhou expressão em todo Baixo Amazonas a partir da segunda metade do século 20, quando grandes serrarias se instalaram na região e passaram a explorar as florestas de várzea (BARROS; UHL, 1997).
} 
e com a população local. A intenção de Ludwig era fundar um projeto pioneiro, "moderno" e que serviria de modelo para o aproveitamento econômico da Amazônia.

O Vale do Jari foi escolhido, fundamentalmente, porque detinha uma imensa área de terras, onde florestas de terra firme, florestas alagadas, várzeas e muitos rios, inclusive alguns com grande potencial hidrelétrico, estavam contidos num único latifúndio. Não foi difícil, com o decisivo e quase irrestrito apoio do governo militar, ao megaempresário americano comprar dos portugueses as terras, benfeitorias e empresas para, no latifúndio criado pelo aviador José Júlio de Andrade, desenvolver seus projetos.

Há uma vasta bibliografia a respeito dos projetos dos militares para a Amazônia entre as décadas de 1960-70, que apenas muito brevemente cabe ser retomada aqui ${ }^{7}$. Na visão dos militares, a Amazônia era um vazio improdutivo a ser conquistado. A floresta era um impedimento para o desenvolvimento, que viria com a instalação de grandes empresas, atraídas por uma política de massivos incentivos fiscais. Nesse período, grandes empresas existentes no Brasil compraram enormes extensões de terra na Amazônia: indústrias, bancos, empreiteiras, empresas de telecomunicação etc. O Projeto Jari era a realização de um desses programas para a Amazônia e, durante muito tempo, contou com o decisivo apoio do alto escalão do governo militar.

Com o desenvolvimento dos projetos de Ludwig, houve, no Jari, uma "desorganização das redes de comercialização dos produtos extrativistas" (GREISSING, 2010, p. 49). Em maio de 1975, a Jari desistiu do arrendamento das filiais de castanha e outros extrativismos, e foi fechando todas as filiais (PINTO, 1986, p. 26). Pela primeira vez, o "grande projeto" instalado no Vale deixa de se ocupar do extrativismo, atividade exercida por aquela população deste os primórdios da colonização.

\footnotetext{
${ }^{7}$ Entre esses estudos, tratam do Projeto Jari: OLIVEIRA, 1995; PINTO, 1986; SAUTCHUK, 1980; GARRIDO FILHA, 1980.
} 
Uma de suas primeiras providências foi a substituição de uma grande área de mata nativa por uma monocultura que pudesse abastecer a fábrica de celulose, que na época estava em construção no Japão. Somente entre 1972 e 1979, 70 mil hectares de floresta nativa foram derrubados com esse fim. A população expropriada ocupante dessas áreas teve que se deslocar, mudandose para onde houvesse floresta, para a área urbana de Almeirim, para o Beiradão que se formava na margem esquerda do Rio Jari (de que trataremos adiante), ou, ainda, para regiões mais distantes (PINTO, 1986). Poucos eram incorporados como mão de obra nas atividades da empresa. Muitos permaneceram longe das suas áreas de origem até o final dos anos 1980, quando começaram a retornar, ocupando (e sendo expulsos) sistematicamente das terras controladas pela empresa, mas não utilizadas por ela.

Outras restrições foram, ainda, implantadas para que não fossem levantadas dúvidas sobre a propriedade das terras que a empresa de Ludwig dizia ser dona: castanheiros foram proibidos de entrar em áreas por eles manejadas há décadas e, ainda em 1969, a Jari criou um setor destinado a impedir o ingresso de "estranhos" que funcionava como uma autêntica polícia particular (PINTO, 1986, p. 92). Mesmo assim, isso não impediu que regatões continuassem a comprar castanha e madeira extraídas por moradores das comunidades tradicionais e nem mesmo que posseiros, atraídos à região pela possibilidade de trabalho na empresa, "tirassem" ${ }^{8}$ terras em meio as áreas de floresta nativa (PINTO, 1986).

Havia de maneira geral na Amazônia, na década de 1970, uma forte tensão entre distintos grupos sociais. Em muitas regiões, empresários investiram os recursos públicos na compra de terras para simples especulação futura e/ou desmataram grandes extensões de florestas. No processo de transferência da terra pública para os grandes grupos econômicos o governo em vários momentos alterou a legislação existente e criou dispositivos legais

8 "Tirar" terra, ou "amansar" terra designa o ato de derrubar a mata, abrir um roçado, limpar o terreno e cultivá-lo. Quem tira ou amansa uma terra, possui, nessas comunidades, uma espécie de direito de procedência sobre a terra, que não deve se confundir com o direito de propriedade. Sua ocupação por outra pessoa está condicionada a licença de quem a tirou ou amansou (MARTINS, 1998). 
extraordinários e de exceção tornando assim possível a apropriação privada de imensas áreas de terras. Dessa forma, a terra pública, habitada por diferentes grupos sociais (colonos, ribeirinhos, índios etc.), foi vendida para os novos investidores, que a adquiria diretamente dos órgãos fundiários do governo ou de particulares, muitas vezes por meios ilícitos, gerando uma série de conflitos. Era frequente que as terras adquiridas fossem demarcadas pelos novos proprietários numa extensão muito maior do que a dos lotes que originalmente haviam adquirido (LOUREIRO et al, 2005).

$\mathrm{Na}$ tentativa de organizar uma resistência ao processo expropriatório, o Movimento Eclesial de Base (MEB) e os sindicatos de trabalhadores rurais (STR) cumpriram o importante papel de apoiar a organização política tanto das populações rurais existentes na região antes da implantação dos grandes projetos, quanto daquelas que chegavam à região em fluxos migratórios induzidos pelos projetos de colonização, que em sua esteira influenciavam a organização de fluxos espontâneos.

No entanto, o processo expropriatório de um lado, e o movimento social em apoio à organização política das populações rurais de outro, tiveram especificidades no Vale do Jari, apresentado como resultado mais visível, o contexto grandioso do projeto capitalista ali instalado e a dificuldade de organização política das populações rurais afetadas pelo projeto.

Enquanto Ludwig implantava seu ambicioso projeto, consolidando a expropriação de uma imensa área de terras, várias modificações normativas e institucionais aconteciam na Amazônia. Em 1970, o INCRA foi criado com a missão de incorporar ao Patrimônio da União as terras devolutas ${ }^{9}$ existentes e reconhecer as posses legítimas, além de implantar as condições de destinação das terras desocupadas. Um ano após a criação do INCRA, foram criados o Programa de Integração Nacional (PIN) e os Projetos Integrados de Colonização

\footnotetext{
${ }^{9} \mathrm{O}$ conceito de terra devoluta foi definido no Art. $3^{\circ}$ da Lei de Terras de 1850, mas pode ser entendido como todas as terras existentes no território brasileiro, que não se incorporaram legitimamente ao domínio particular, bem como as já incorporadas ao patrimônio público, porém não afetadas a qualquer uso público.
} 
(PIC), tendo ainda sido editado o Decreto Lei $\mathrm{N}^{\circ} 1164$, que tornou possível a federalização das terras presentes a $100 \mathrm{~km}$ de cada lado do eixo das rodovias federais existentes ou planejadas nos estados pertencentes à Amazônia Legal ${ }^{10}$. O conjunto de programas e políticas implantado pelo governo militar alterou significativamente o mapa fundiário da Amazônia e o panorama de atuação dos órgãos fundiários estaduais, pois grande parte das áreas antes a estes jurisdicionadas passou a ser de responsabilidade do INCRA. No Pará, após a edição do Decreto-Lei 1164, aproximadamente 70\% das terras passaram a ser de domínio da União. Nas áreas federalizadas, o Estado passou a utilizar o processo discriminatório de terras devolutas da União, disciplinado na Lei no 6.383 de 07 de dezembro de 1976, com o fim de identificar, arrecadar e destinar as terras públicas.

Para a "sorte" de Ludwig, a região do vale do Jari ficara de fora da área federalizada, não sendo, pelo Decreto-Lei 1164/71, reconhecida como área prioritária para a regularização fundiária. Ou seja, essa região não se encontrava na área de atuação do INCRA e continuava sob responsabilidade do Instituto de Terras do Pará (ITERPA). Anos depois, diante de um quadro político que obrigava a Ludwig regularizar as terras do projeto, foi criado em 1980 o Grupo Executivo de Terras do Baixo Amazonas (GEBAM). Na mesma época, na região do Araguaia-Tocantis, o governo militar criava o Grupo Executivo de Terras do Araguaia-Tocantis (GETAT) ${ }^{11}$.

O GEBAM foi criado para atuar no baixo amazonas, fundamentalmente no vale do Jari, quando o estado do Pará dificultava a regularização das terras do

10 O Decreto-Lei no 1.164, de 01 de abril de 1971, declarou ser indispensáveis à segurança e ao desenvolvimento nacional as terras devolutas situadas na faixa de 100 quilômetros em cada lado do eixo das rodovias federais implantadas ou projetadas na Amazônia Legal. Havia a pretensão de incorporar as terras públicas devolutas ao Patrimônio da União numa área de aproximadamente de 2,2 milhões de $\mathrm{km}^{2}$, fato que reduziu o domínio dos estados integrantes da Amazônia Legal Pará Maranhão, parte norte de Goiás (atual Tocantins), parte norte dos estados do Mato Grosso, Amapá, Roraima, Amazonas e Rondônia Tratava-se de uma estratégia para viabilizar a integração nacional, formulada a partir do entendimento de que a federalização das terras estaduais consistia em um instrumento importante para o Governo Federal controlar o processo de ocupação na Amazônia.

${ }_{11}$ O GEBAM e o GETAT eram subordinados a Secretaria Geral do Conselho de Segurança Nacional. Tinham a missão de coordenar grupos regionais com plenos poderes de alienação de imóveis, de regularização de posses ilegítimas, de discriminação de terras devolutas ilegalmente ocupadas, bem como a resolução de projetos pendentes para obtenção de títulos ou licenças de ocupação de áreas. 
Projeto de Ludwig, pois por maior que fosse a intenção política de regularizar as áreas, as análises jurídicas da situação fundiária chegavam à conclusão da inviabilidade legal em fazê-lo.

Por outro lado, diferente do sudeste paraense, onde movimentos sociais denunciavam os inúmeros conflitos violentos, as arbitrariedades dos processos de arrecadação e destinação de terras executados pelo GETAT e mobilizavam a organização de distintas populações rurais, no Jari, pouca visibilidade era dada aos conflitos existentes no interior do latifúndio. Ludwig, com apoio do GEBAM e da empresa de segurança armada que fazia a guarda patrimonial do latifúndio, conseguia desarticular as tentativas de implantação ali da estrutura de organização social desenvolvida em outras regiões pelos MEBs e STRs, que no Jari tiveram pouca ou nenhuma importância. E continuava a operar o latifúndio sem conseguir regularizá-lo.

Mesmo assim, as poucas vilas formadas por extrativistas, pescadores e pequenos criadores não afetados diretamente pelos projetos agropecuários, continuaram existindo. Não organizados em Vilas, muitos grupos familiares ocupavam distintas regiões do latifúndio, adaptando-se as mudanças impostas por Ludwig. A esses grupos familiares somavam-se muitos migrantes, conforme comentado a seguir.

\section{MIGRAÇÃO, DIFERENCIAÇÃO ECONÔMICA E PECUARIZAÇÃO}

Em função das novas estratégias econômicas a orientarem a exploração do latifúndio e com a priorização de atividades agropecuárias e industriais que demandavam mão de obra, tornou-se necessária a contratação de milhares de trabalhadores para a derrubada da mata nativa e o plantio de florestas homogêneas na região de Monte Dourado, bem como para a implantação do projeto de arroz e gado, na região do Rio Arroyolos. A Jari instaurou, então, um 
novo modo de recrutar mão de obra: estabeleceu uma rede de empreiteiras em estados do nordeste e no sul/sudeste do Pará para aliciar trabalhadores dando início a um dos mais intensos processos de migração induzida por uma empresa em toda história da Amazônia. A região passou, a partir do início dos anos 1970, por uma profunda transformação ao ser o destino de milhares de maranhenses, cearenses, piauienses e migrantes de outros estados, a grande maioria homens entre 20 e 30 anos.

Em meados dos anos 1970, sérios conflitos trabalhistas aconteciam entre os funcionários do Projeto e as empresas de Ludwig, devido às insalubres condições de trabalho (PINTO, 1986; OLIVEIRA, 1995). Quase cinquenta anos depois da Revolta do Cezário, e apesar de todas as alterações ocorridas na estratégia de gestão do latifúndio, trabalhadores sujeitados procuravam dar visibilidade aos mecanismos de dependência social e de exploração da força de trabalho a eles imposta.

Em 1974, para racionalizar a contratação de mão de obra e diminuir os problemas com a previdência social e com a crescente cobertura feita pela mídia nacional e internacional acerca dos conflitos trabalhistas no latifúndio da Jari, foi criado o SASI (Serviços Agrários e Silvioculturais Ltda.), empresa que ficou responsável por conduzir o processo de contratação de mão de obra e distanciar a Jari dos escândalos.

Como havia grande sazonalidade na demanda de mão de obra, a maioria dos contratos trabalhistas era temporária. Com exceção parcial aos garimpos existentes no alto curso do rio Jari, não havia alternativas de trabalho na região que pudessem manter ocupadas as levas de trabalhadores quando os contratos terminavam, e que, na maioria dos casos, não dispunha de recursos financeiros para poder retornar às suas regiões de origem. Além disso, toda a estratégia de criação de silvivilas ${ }^{12}$ adotada pela Jari para abrigar a mão de obra volante não

\footnotetext{
${ }^{12}$ As Silvivilas eram pequenas localidades que disporiam de toda infraestrutura necessária (escola, supermercado, posto médico etc.) e abrigariam engenheiros, administradores, assistentes sociais, médicos, enfermeiros, capatazes, motoristas, operadores de máquinas e trabalhadores com suas famílias. Foram planejadas dez silvivilas no Pará e três no Amapá, porém, até 1982, havia apenas três: Planalto (1713 pessoas), São Miguel (1124) e Bananal, que acabara de ser construída (LINS, 1991, p. 157). Além disso, as casa destinadas aos trabalhadores braçais não dispunham, por exemplo, de fossa e água encanada (PINTO, 1986, p. 106). A maioria dos trabalhadores, principalmente os braçais, permanecia em acampamentos provisórios e em péssimas condições.
} 
foi bem sucedida, ou seja, mesmo os trabalhadores empregados, contratados formalmente ou não, não dispunham de infraestrutura de habitação adequada que os pudesse receber.

Essas pessoas foram, então, se acumulando na margem esquerda do Rio Jari, no município de Mazagão-AP, em precárias condições, formando, desordenadamente sobre palafitas, o "beiradão" e o "beiradinho".

O esforço de induzir fluxos migratórios gerava, paralelamente, fluxos espontâneos. Mais do que a possibilidade de conseguir trabalho imediato na Jari, havia, para boa parte dos migrantes nordestinos, o sonho de obter terra própria no norte brasileiro, sonho muito alimentado pela propaganda oficial do governo militar. Mesmo entre muitos daqueles que chegavam à região com a garantia do emprego no Projeto Jari, o trabalho assalariado funcionava como uma estratégia de acumulação financeira para a compra da terra.

A partir da segunda metade dos anos 1970, à medida que cresciam o Beiradão e o Beiradinho, aumentava também o número de posseiros ocupando terras em várias regiões do latifúndio, processo que fugia ao controle da empresa, por maior que fossem os mecanismos de opressão por ela utilizados. Genericamente, a posse poderia ser tirada em alguma área de mata virgem ou comprada de alguém que a tivesse estabelecido anteriormente, migrante recente ou posseiro das Vilas existentes. Estabeleciam-se roçados de mandioca e culturas anuais, além de algumas benfeitorias. Parte dessas posses, quando descobertas pela empresa mesmo depois de vários anos, era violentamente destruída, com a utilização do seu aparato de segurança privado. Depois de certo período, parte dos posseiros expulsos voltava a ocupar novas áreas, podendo ou não ser novamente expulsos pela Empresa.

Contraditoriamente, quanto mais aumentava o uso da violência contra posseiros, menos a empresa parecia ter condições de comprovar a propriedade da terra, conforme mostravam os relatórios publicados pelo Iterpa a partir de 1978, discutidos mais adiante. 
Em 1982, após desembolsar 1,3 bilhões de dólares, acumular prejuízos e ver aumentar a pressão para que o Projeto fosse nacionalizado, Ludwig vendeu o Jari por 80 milhões de dólares para um consórcio de empresas brasileiras liderado pelo Grupo Caemi. A transição foi organizada pelo governo e dependeu do apoio massivo do Banco do Brasil e BNDES ${ }^{13}$. Durante as décadas de 1980 e 1990, apenas em 1994 a Jari Celulose teve lucro (CAVALCANTI, 1999) e viu sua dívida chegar a 415 milhões de dólares (ROSENBURG, 2007).

Foram intensas as mudanças desencadeadas no Vale do Jari com a implantação do Projeto. No intervalo de seis anos entre 1977 e 1983, a população de Monte Dourado passou de 2.096 para 8.500 habitantes. No Beiradão, nesse mesmo período, as estimativas são de um salto de 5 mil para 12 mil habitantes, e, no Beiradinho, de 884 para 4 mil (PINTO, 1986, p. 92).

Com o aumento da aglomeração nessas áreas, o Estado do Amapá criou, em 1987, o município de Laranjal do Jari, englobando a região conhecida por Beiradão e, em 1994, instituiu o município de Vitória do Jari, incorporando a região conhecida por Beiradinho. A maior contribuição para a composição da população urbana desses dois municípios adveio dos fluxos migratórios de nordestinos relacionados à implantação e exploração, nos anos 1970-80, do complexo agroindustrial da Jari. Como já dito, parte desses migrantes manteve vínculos trabalhistas, temporários ou não, com a Jari ou suas empreiteiras; outros jamais chegaram a trabalhar na empresa.

O Beiradão, em Laranjal do Jari, constituiu-se, assim, como uma alternativa de sobrevivência para um grande número de migrantes e posseiros expropriados pela Jari, que lá se empregavam nos comércios que surgiam ou trabalhavam de pedreiros, carpinteiros, funileiros etc. Foi também no Beiradão que pequenos comerciantes começaram a se destacar e se tornaram médios e grandes empresários em Laranjal do Jari. Uma parcela deles fazia parte do grupo de migrantes levada pela própria empresa: alguns trabalharam por longos períodos na Jari, depois passaram a prestar serviços a ela e, anos mais tarde,

13 "Juntos, o BB e o BNDES colocaram mais de 200 milhões de dólares para cobrir dívidas deixadas por Ludwig. Além disso, O BB entrou sozinho com mais 180 milhões de dólares em ações preferenciais, sem direito a voto. Foi uma montanha de dinheiro público torrada na selva." (CAVALCANTI, 1999). 
compuseram suas empresas; outros poucos nunca trabalharam para a Jari, tendo acumulado capital em serviços prestados no Beiradão, muitas vezes nos garimpos, enquanto tentavam manter suas posses nas áreas rurais ${ }^{14}$.

A partir dos anos 1990, com o acirramento da legislação ambiental, em vários momentos as posses passaram a ser incentivadas pela empresa, a partir da criação de projetos de colonização privada em áreas cuja titularidade ainda hoje é desconhecida. Nesse processo, a pecuária era estimulada pela empresa. O objetivo por trás da colonização era o acesso à madeira para utilizá-la como fonte de energia na caldeira da fábrica de celulose. Nesse sentindo, em 1994, foram criadas, com a ajuda da empresa, a COMPEJ (Cooperativa Mista dos Produtores e Extrativistas do Jari) e a ACOPREN (Associação Comunitária dos Produtores Rurais da Estrada Nova), para fins de facilitação de retirada de madeira das posses dos agricultores.

A COMPEJ assentava as famílias e a empresa pagava ao escritório do IBAMA, criado em Monte Dourado em 1992, a autorização para fazer a derruba. O acordo previa que a Jari ficaria com a madeira, os agricultores indicados por ela com a terra e seria responsabilidade da empresa a abertura e manutenção dos ramais. O acordo foi rompido em 1997, diante da negativa da empresa em fazer a manutenção dos ramais no momento em que a madeira em toda essa região já havia acabado. Como nunca houve repasse de documentação aos colonos, anos depois a Jari tentou persuadi-los a saírem dessas áreas, e hoje, tenta fazê-los aderir ao cultivo de eucalipto por meio do fomento florestal.

Os maiores posseiros em algumas regiões do latifúndio, com destaque para a Estrada Nova, são atualmente grandes e médios comerciantes de Laranjal do Jari e Monte Dourado, que junto a alguns funcionários públicos graduados, contribuem com a pecuarização e a concentração fundiária por que passa essa região nos últimos 20 anos.

14 Além da vigília constante da guarda patrimonial, outros fatores tornavam praticamente impossível a permanência constante das famílias na terra: não havia transporte, acesso a saúde e educação. Essa estratégia de impedir que o município implemente do interior do latifúndio bens e serviços básicos continua em operação com o Grupo Orsa. 


\section{GRUPO ORSA E O LATIFÚNDIO}

A partir de 2000, o Grupo Orsa, umas das principais organizações brasileiras do setor de madeira, papel e embalagens, com atuação no mercado de produtos florestais não-madeireiros, assumiu a área e a dívida acumulada pelo Projeto Jari. O Grupo é composto pelas empresas Jari Celulose, Orsa Florestal, Ouro Verde e a Fundação Orsa.

A divisão de celulose, instalada na Vila Munguba, em Almeirim, é hoje a única fábrica do setor no mundo com certificação 100\% FSC (Forest Stewardship Council), órgão reconhecido internacionalmente como o principal certificador de boas práticas florestais.

A Orsa Florestal é responsável por explorar o maior plano de manejo florestal do mundo, que, certificado desde 2004 pelo FSC, é hoje o maior projeto privado de exploração da floresta nativa tropical certificada no planeta, com aproximadamente 545.000 hectares.

Recentemente, o Grupo Orsa adquiriu o controle acionário da Ouro Verde, uma das empresas líderes do mercado de produtos florestais não-madeireiros, que atua na região procurando regular o mercado de castanha. As espécies oleaginosas e o cacau nativo estão entre seus projetos de prospecção.

Nas várzeas e campos, a criação de búfalos conduzida pelo Grupo Orsa envolve milhares de hectares e o trabalho de dezenas de "peões".

A Fundação Orsa é a empresa social do grupo, trabalhando com o desenvolvimento de programas e projetos sociais, inicialmente relacionados aos temas infância e adolescência. Há cerca de cinco anos, iniciou projetos na área agrícola e florestal, aplicando programas de fomento a produção florestal, notadamente, onde há possibilidade de cultivo de eucalipto e extrativismo de produtos não-madeireiros.

A Estrada Nova é, hoje, uma das regiões em que a Fundação Orsa mais incentiva o fomento florestal do eucalipto. Pecuaristas e o Grupo Orsa vêm, grosso modo, conduzindo um tácito acordo: aqueles destinam parte de suas terras ao plantio do eucalipto e esta não move ações de reintegração de posse 
contra eles. Recentemente, algumas dessas ações movidas contra pecuaristas que gozam de certa popularidade com os pequenos posseiros levaram a mobilização destes, que, com apoio dos pecuaristas, divulgaram em cadeia nacional, numa entrevista à Rádio Amazônia, os problemas fundiários do Vale do Jari.

Não é difícil perceber entre grandes e pequenos posseiros na Estrada Nova relações de compadrio e clientelismo que vêm reeditando vínculos de dependência social, e favorecendo a pecuarização e a concentração fundiária em nome dos grandes, além da migração dos pequenos para novas frentes de ocupação no interior do latifúndio ou o assalariamento como peões nas fazendas de gado.

O avanço da pecuária na região da Estrada Nova, que na década de 1990 foi incentivada pela empresa controladora do latifúndio, contribui de certo modo, com um discurso muito utilizado pelo Grupo Orsa: é o seu aparato de segurança patrimonial e o plano de manejo em operação que evitam e barram o desflorestamento no interior do latifúndio.

Segundo o próprio Grupo Orsa, suas empresas atuam de forma integrada, incorporando modelos de ação economicamente viáveis, socialmente justos e ambientalmente corretos, numa visão ampliada de sustentabilidade, que iria além do comprometimento com os negócios e com as comunidades onde eles estão inseridos, tudo com respeito à legislação nacional ${ }^{15}$. Porém as várias disputas judiciais e os inúmeros conflitos existentes com as comunidades do Vale do Jari parecem contar outra história, conforme discutido a seguir.

\footnotetext{
${ }^{15}$ Ver: <http://www.grupoorsa.com.br>. Acesso em: 03 fev. 2011.
} 


\section{A REINVENÇÃO DO LATIFÚNDIO EM TEMPOS DE "CAPITALISMO VERDE"}

O histórico de formação do latifúndio no Vale do Jari pode ser observado sob vários aspectos. Do ponto de vista socioeconômico houve a transição do foco nas atividades extrativistas de produtos não-madeireiros para a extração madeireira e para o complexo agroindustrial orientado à produção de celulose. Se, no seu início, eram as condições de dependência criadas entorno do aviamento que regulavam as relações entre o "patrão", Zé Júlio de Andrade, e camponeses, o latifúndio, durante o governo militar, experimentou uma fase de relacionamento contratual - formal e informal - de grandes levas de trabalhadores com o novo "patrão", Ludwig, que já não era aviador, mas um dos grandes representantes do "moderno" capitalismo mundial.

Depois de um período de intensa crise econômica nos anos 1980-90, mais recentemente, o latifúndio do Jari entra numa nova fase, em que as duas estratégias anteriores são retomadas e modernizadas, em nome de certo capitalismo supostamente dotado de responsabilidade socioambiental. De um lado, são mantidas e ampliadas as relações contratuais entre as empresas componentes do Grupo Orsa e suas empreiteiras com os milhares de empregados que garantem a produção das florestas homogêneas, o fabrico da celulose e a criação bovina. De outro lado, as atividades de exploração de diversos produtos da floresta nativa, embora também mantidas a partir de relações contratuais com os operadores de moto-serra, funcionários da serraria e técnicos florestais, acontecem mediante o discurso de inclusão social das comunidades inseridas na área de exploração. Talvez se possa supor que, aqui, as relações de dependência e clientelismo, típicas do aviamento, são reeditadas e atualizadas pela participação das comunidades em programas e projetos desenvolvidos pela empresa social do Grupo - a Fundação Orsa - que, em troca, promete não expulsá-las da terra. 
Latifúndio, conflito e desenvolvimento no Vale do Jari: do aviamento ao Capitalismo Verde, pp. 114-140.

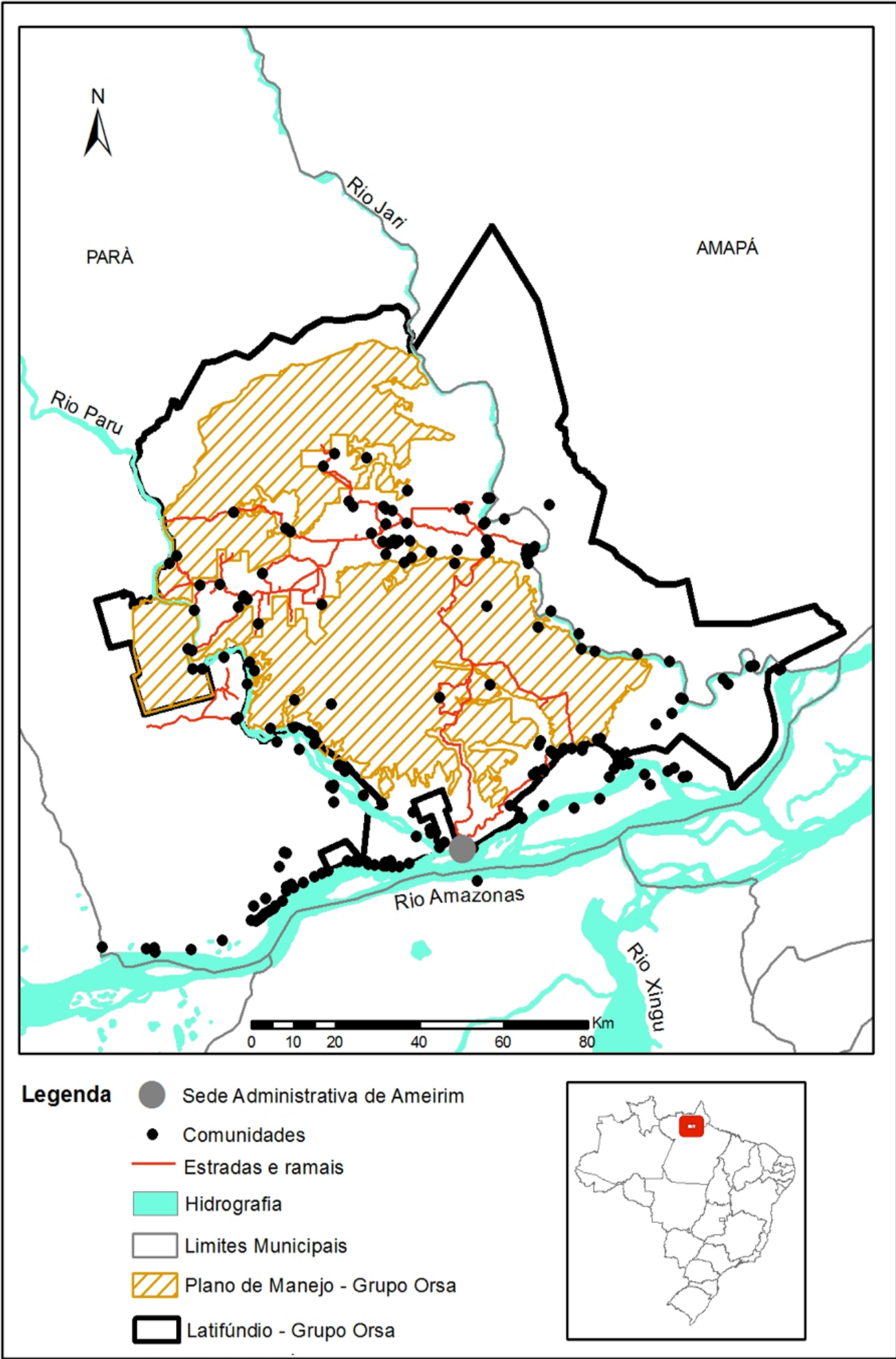

Fonte: IBGE, IBAMA, STTR-Santarém trabalhos de campo 
Depois de um período de intensa crise econômica nos anos 1980-90, mais recentemente, o latifúndio do Jari entra numa nova fase, em que as duas estratégias anteriores são retomadas e modernizadas, em nome de certo capitalismo supostamente dotado de responsabilidade socioambiental. De um lado, são mantidas e ampliadas as relações contratuais entre as empresas componentes do Grupo Orsa e suas empreiteiras com os milhares de empregados que garantem a produção das florestas homogêneas, o fabrico da celulose e a criação bovina. De outro lado, as atividades de exploração de diversos produtos da floresta nativa, embora também mantidas a partir de relações contratuais com os operadores de moto-serra, funcionários da serraria e técnicos florestais, acontecem mediante o discurso de inclusão social das comunidades inseridas na área de exploração. Talvez se possa supor que, aqui, as relações de dependência e clientelismo, típicas do aviamento, são reeditadas e atualizadas pela participação das comunidades em programas e projetos desenvolvidos pela empresa social do Grupo - a Fundação Orsa - que, em troca, promete não expulsá-las da terra.

O Grupo Orsa ocupa uma área que se estende por três municípios em dois estados brasileiros. Como todos os grandes latifúndios da Amazônia, ele abriga conflitos relacionados à posse da terra que a empresa, por sua vez, controla com poder de polícia.

A imensa maioria das ocupações no interior do latifúndio são posses, pouquíssimos possuem título de propriedade da terra. Há, como exceções, cerca de 120 títulos distribuídos nos anos 1990 em um trecho da Estrada Nova e um ou outro caso isolado, como algumas permutas concedidas pelo Iterpa e algumas fazendas de gado nas várzeas.

Um dos fatores que desestimularam Ludwig a continuar o Projeto Jari, foi a impossibilidade de regularizar as terras, mesmo com o apoio do Governo Militar. Em 26 de novembro de 1976, a Jari Florestal e Agropecuária Ltda., hoje Jari Celulose S/A, requereu ao Iterpa, através do processo $n^{\circ} 05562 / 76$, a legitimação de 33 posses, que juntas somavam 2.786.237 hectares. A empresa conseguiu comprovar a cadeia sucessória de 19 dessas posses, enquanto outras 
14, inclusive a Fazenda Saracura com seus 2.600 .000 hectares, não foram regularizadas por não cumprirem especificações elementares.

Após consolidar a compra da Jari Celulose, o Grupo Orsa inseriu a exploração dos produtos florestais madeireiros em sua estratégia econômica. Diante desse novo cenário, em 2001, a Jari Celulose empreendeu a unificação de todos os títulos inerentes à formação do latifúndio, reunindo títulos de propriedade, de posse e de aforamento em uma mesma matrícula no Cartório Imóveis do município de Monte Alegre, transformando-os em uma única propriedade de cerca de 911 mil hectares.

Após a unificação dos títulos, a Jari Celulose elaborou e apresentou ao Instituto Brasileiro do Meio Ambiente e dos Recursos Naturais Renováveis (Ibama) um Plano de Manejo Florestal Sustentável a ser desenvolvido em 545 mil hectares pertencentes ao que seria a Reserva Legal do latifúndio, e que posteriormente passou a ser gerido pela Orsa Florestal, com base num Contrato de Comodato assinado entre as duas empresas.

A Promotoria Pública da Comarca do município de Almeirim, porém, instalou a Ação Civil Pública 02/2001 com o objetivo de investigar indícios de fraude no processo de unificação das terras que compõem o latifúndio da Jari Celulose no município. Como consequência, em 2004 a Corregedoria das Comarcas do Interior decidiu pelo cancelamento da matrícula imobiliária unificada em Monte Alegre, puniu a tabeliã, irmã de um dos diretores da empresa, e reconheceu o direito da empresa às benfeitorias, mas não à propriedade das terras. Tal decisão deu início a uma intensa batalha judicial entre a empresa e o Governo do Estado do Pará, que desde em 1978 reconhecia como públicas boa parte dessas terras.

Em 2004, com a restrição do IBAMA em conceder a liberação dos Planos de Manejo Florestal apenas em áreas com situação fundiária regularizada, o Grupo Orsa entrou com ação demarcatória no Fórum da Comarca de Almeirim. A requisição foi negada por sentença, sendo considerada ilegítima.

Em 13 de junho de 2005, o Desembargador Enivaldo da Gama Ferreira deu, em $2^{a}$ instância, provimento para anular a sentença e todos os atos 
praticados a partir dela, a fim de que prosseguisse a ação demarcatória e, baseando-se no art. 44 do Ato das Disposições Constitucionais Transitórias da Constituição do Estado do Pará. Tal decisão motivou, em 2005, que a Procuradoria Geral do Estado do Pará entrasse no TJE com uma ação declaratória de inexistência de domínio contra a Jari e encaminhasse ao STF uma Ação de Inconstitucionalidade para dois artigos da Constituição do Estado que serviam de base legal para a Jari tentar regularizar suas áreas de pretensão. Ainda em 2005, o STF julgou procedente a Ação Direta de Inconstitucionalidade, derrubando toda a argumentação jurídica do Grupo Orsa.

Mesmo assim, em 21 de dezembro de 2006, as empresas Jari Celulose S/A, Orsa Florestal S/A e o Governo do Estado do Pará, firmam um termo de compromisso, visando uma solução amigável para o problema possessório existente na faixa de abrangência do "Projeto Jari", em Almeirim. Em tal documento, ficou consignado que deveriam ser respeitadas e excluídas da área de manejo florestal as áreas ocupadas pelas comunidades tradicionais, tendo a Jari prometido colaborar com a titulação das posses dessas comunidades. Assim, em 23 de julho de 2007, foi assinado um termo de compromisso entre o Iterpa, a Orsa Florestal e a Jari Celulose visando "garantir a regularização fundiária das comunidades inseridas na faixa de abrangência do 'Projeto Jari' no município de Almeirim e possibilitar a continuidade da execução do Plano de Manejo Florestal Sustentável". O Plano de Manejo seguiu em atividade, mas nada foi feito pela regularização das áreas das comunidades.

As fraudes que cercam o plano de manejo florestal foram apuradas pela polícia federal, a partir do processo aberto pela Promotoria de Almeirim em 2001. Chegou-se à conclusão, em 2009, que o Grupo Orsa não era proprietário da maior parte das terras abrangidas pelo Plano de Manejo, denunciando que ocorria grilagem de terras públicas. Em maio de 2011, o Ministério Público Federal de Santarém-PA, encaminhou a Justiça Federal queixa-crime por crime de estelionato cometido por um dos diretores da empresa no processo de unificação das matrículas.

Mesmo em meio a todas essas contestações de seu direito à ocupação daquelas áreas, em 2010, a empresa inaugura uma nova fase de violentas ações 
de reintegração de posse em várias comunidades do Vale do Jari, levando ao chão benfeitorias e cultivos de dezenas de famílias de pequenos agricultores e alguns pecuaristas. E mais: o Plano de Manejo Florestal, realizado em áreas irregularmente apropriadas, continua em operação até hoje, ainda certificado pelo FSC.

O Termo de Compromisso assinado entre a Jari Celulose, a Orsa Florestal e o governo do Estado do Pará, vem sendo renovado anualmente, sem que nenhuma comunidade tenha sido regularizada.

É também interessante notar outra forma de legitimação do latifúndio do Jari: a produção cartográfica que o retrata, principalmente aquela elaborada pela própria empresa, mas também, recentemente, por organizações nãogovernamentais (ONGs) envolvidas com o Projeto Almeirim Sustentável.

Em ambas, a cartografia dá visibilidade à dimensão territorial do latifúndio, à distribuição espacial das atividades produtivas e de preservação ambiental (principalmente quando retratadas pela empresa), e às potencialidades para o desenvolvimento de cadeias produtivas alternativas, vinculadas territorialmente a algumas comunidades inseridas no latifúndio, quando retratados, mais recentemente, pelas ONGs.

Tal cartografia impressiona mais pelo que omite do que pelo que representa. Mapas podem ser entendidos enquanto um tipo específico de linguagem de poder e de discurso sobre o controle do território (ACSELRAD, 2008). Nesse sentido, a omissão nesta produção cartográfica, proposital ou não, do grande número de comunidades existentes no latifúndio, bem como das atividades produtivas de comunidades não parceiras da empresa que o controla, confere invisibilidade à maior contradição do latifúndio e, logo, ao maior conflito existente no seu interior: a presença histórica de milhares de pessoas que lutam por assegurar um pedaço de terra, que torne minimamente viável sua sobrevivência. E, do ponto de vista da sobrevivência das comunidades ali existentes, essa cartografia torna-se, inevitavelmente, uma antítese do caminho de um desenvolvimento sustentável que se preocupa em representar. 


\section{CONSIDERAÇÕES FINAIS}

O Vale do Jari vem acumulando há mais de um século uma população majoritariamente pobre que, quando não inserida nos grandes empreendimentos que ocuparam a região, vive de atividades marginais a estes ou nas áreas por eles deixadas de lado, de onde são expulsas quando a expansão da grande empresa exige terreno. Essa situação se perpetua e, ainda hoje, no latifúndio criado por José Júlio de Andrade, agora gerido pelo Grupo Orsa, acontecem conflitos fundiários e direitos elementares, como o acesso à saúde e à educação, são negados.

Zé Júlio enriqueceu com a exploração da floresta e do trabalho de extrativistas. Ludwig derrubou milhares de hectares de florestas para a instalação do seu projeto. Em sua época, a floresta era encarada como um impedimento ao desenvolvimento e vultosos incentivos públicos foram concedidos para empresas que cuidaram de sua remoção. Milhares de extrativistas que viviam da floresta foram dela expulsos, e ajudaram a compor no vale do Jari a formação de enclaves populacionais que até hoje desfrutam dos piores índices nacionais de desenvolvimento econômico, humano e social o Beiradão que originou Laranjal do Jari, e o Beiradinho, a partir de onde se formou Vitória do Jari.

Diferente da época do governo militar, atualmente, as florestas são consideradas condição essencial ao desenvolvimento, que em sua adjetivação de sustentável, impõe uma série de normas legais para seu uso racional. Entre elas aparecem com destaque o respeito às populações rurais e o cumprimento da legislação ambiental. Para reforçar os valores técnicos e um discurso cívico moralizador vinculados ao desenvolvimento da exploração florestal, várias organizações monitoram e premiam iniciativas de responsabilidade socioambiental, distribuindo selos verdes e certificações de boas práticas.

No latifúndio criado pelo coronel Zé Júlio, está em operação o maior plano de manejo florestal madeireiro certificado do mundo, sendo constantemente divulgado como exemplo de boas práticas socioambientais, apesar dos vários 
conflitos, das disputas judiciais e do não cumprimento das cláusulas do termo de compromisso assinado pela Empresa e ratificado pelo estado do Pará, que sustentam a "legalidade" da exploração.

Os vários prêmios de sustentabilidade ambiental e responsabilidade social conferidos a empresa ${ }^{16}$ e a certificação concedida pelo FSC ao Plano de Manejo Florestal acabam, na prática, por legitimar o latifúndio. Neles, as inúmeras irregularidades fundiárias e os conflitos socioambientais são omitidos, permitindo ao Grupo Orsa sustentar a alcunha de "empresa verde" e socialmente responsável.

Assim como na época de José Júlio de Andrade, o que hoje sustenta economicamente o latifúndio é a exploração econômica da floresta nativa. Comum às duas épocas, apesar dos cem anos que as separam, são também a pobreza e a situação de conflito em que se encontram as populações rurais presentes no seu interior. Zé Júlio, talentoso aviador, consolidou poder político, tornou-se senador e registrou terras em seu nome, que se cartografadas, iriam até o mar do caribe. Tinha como plataforma política o desenvolvimento econômico do Baixo Amazonas. Na base do seu poder estava o funcionamento dos barracões, que mantinham os extrativistas escravizados pela dívida.

O Grupo Orsa, cujos dirigentes assimilaram conceitos chaves associados ao manejo empresarial sustentável dos recursos naturais e que pela qualidade dos discursos e dos planos corporativos elaborados ganham prêmios nacionais e internacionais, luta judicialmente para comprovar a validade dos títulos de terras forjados por Zé Júlio. Possuem como plataforma política o desenvolvimento regional e a valorização dos direitos e saberes das populações rurais. Na base do seu poder estão os arranjos institucionais que defendem a salvaguarda da floresta a partir de mecanismos de mercado e um conjunto de discursos, imbuídos de valores ecológicos e de uma moral desenvolvimentista

\footnotetext{
${ }^{16}$ Ver, por exemplo: "Grupo Orsa recebe Prêmio Brasil de meio ambiente". Disponível em: <http://www.fundacaoorsa.org.br/pt/arquivos/namidia/namidia_314176750.pdf>. Acesso em: 17 set. 2011; e "Sergio Amoroso, presidente do Grupo Orsa, recebe Prêmio 'Faz Diferença'". Disponível em: <http://www.revistafator.com.br/ver_noticia.php?not=6908>. Acesso em: 17 set. 2011.
} 
139 AGRÁRIA, São Paulo, No. 18, 2013 FOLHES, R. e CAMARGO, M. L.

supostamente includente das populações rurais inseridas nas áreas de impactos dos empreendimentos.

Em meio a discursos modernizados e a novos arranjos institucionais o latifúndio perpetua-se na estrutura agrária da Amazônia, mantendo na pobreza milhares de pequenos agricultores. E hoje, mais do que no passado, é premiado por isso.

\section{REFERÊNCIAS BIBLIOGRÁFICAS}

ACSELRAD, Henri (org.). Cartografias sociais e território. Rio de Janeiro: Universidade Federal do Rio de Janeiro, Instituto de Pesquisa e Planejamento Urbano e Regional, 2008. 168 p. (Coleção Território, ambiente e conflitos sociais; n. 1).

ARAÚJO, R., LENA, P. (org.). Desenvolvimento sustentável e sociedades na Amazônia. Belém: MPEG, 2011. 510 p. : il. (Coleção Eduardo Galvão).

BARROS A.C.; UHL, C. Padrões, problemas e potencial da extração madeireira ao longo do rio Amazonas e do seu estuário. Vol. 4, Série Amazônia, n. 4. Belém: IMAZOM, 1997. 42 p.

BENATTI, J. H. Posse agroecológica e manejo florestal. Curitiba: Juruá, 2003.

BROERS, Leo. "Sustainable on paper: the eucalyptus plantations of Bahia, Brazil". $2010 . \quad$ Disponível em: <http://www.kauri.be/Uploads/Documents/doc_0966.pdf>. Acesso em: 16 set. 2011.

CAVALCANTI, K.; FERRAZ, S. "Vende-se por 1 dólar". Veja, Ed. Abril, 07 jul. 1999. Disponível em: <http://veja.abril.com.br/070799/p_074.html>. Acesso em: 29 set. 2011.

GARRIDO FILHA, I.B.M. O Projeto Jari e os capitais estrangeiros na Amazônia. Petrópolis: Vozes, 1980.

GREISSING, Anna. Revista Universidade, Sorocaba, v. 36, n. 3, p. 43-75, dez. 2010.

IFT, IMAFLORA. Diagnóstico Econômico Ecológico de Almeirim. Belém: IFT; Imaflora, 2010.

LINS, C. Jari: 70 anos de história. Almeirim: Dataforma; Prefeitura Municipal de Almeirim, 1991. 
LOUREIRO, V. R.; PINTO, J.N.A. A Questão Fundiária na Amazônia. Estudos Avançados 19 (54), 2005.

MARTINS, José S. O cativeiro da terra. São Paulo: Hucitec, 1998.

OLIVEIRA, A.U. Amazônia: monopólio, expropriação e conflitos. 5. ed.; Campinas: Papirus, 1995.

PINTO, Lúcio F. Jari: toda a verdade sobre o projeto de Ludwig. São Paulo: Marco Zero, 1986.

ROSENBURG, Cynthia. "O desafio de salvar o Jari". Época Negócios, Ed. Globo, edição 4, 26 jul. 2007. Disponível em: <http://epocanegocios.globo.com/Revista/Epocanegocios/0,,EDG775478384-4,00-O+DESAFIO+DE+SALVAR+O+JARI.html>. Acesso em: 29 set. 2011.

SANTOS, Roberto. História econômica da Amazônia. São Paulo: TAQ, 1980.

SAUTCHUK, J.; CARVALHO, H.M.; GUSMÃO, S.B. Projeto Jari: a invasão americana. São Paulo: Brasil Debates, 1980. 